\title{
PREPARATION OF GALACTOSE
}

\author{
By E. P. Clark
}

ABSTRACT

Owing to the large demand made by bacteriologists for specifications and data on galactose and its derivatives, a convenient method is described for preparing galactose from lactose so that this work may be undertaken.

One $\mathrm{kg}$ of lactose is hydrolyzed by boiling two hours with 2.5 liters of water and 50 $\mathrm{g}$ of sulphuric acid. The solution is neutralized with barium carbonate, filtered and concentrated. The galactose is crystallized from the resulting syrup by the addition of a mixture of I part of ethyl and 2 parts of methyl alcohol. The yield of crude sugar is about 27 per cent.

During the past few years there has arisen a demand for accurate data on the physical properties of the less common sugars. Coincident with this demand is also the constantly increasing use of these materials and the necessity for more economical methods of preparation. As the result of these conditions, this Bureau has had numerous requests for information on the economical production of galactose, as well as for an accurate value of its specific rotation. In order to bring this about, as well as to supply the demand for a standard sample of this material, an investigation of the subject was undertaken.

A number of methods for preparing galactose ${ }^{1}$ have been reported, but partly because the details of procedure are not given with sufficient exactness, and partly because, in many cases, unnecessarily drastic measures have been recommended which add to the cost and reduce the yield, these methods are not satisfactory. Recently, an unpublished method, originated in the Bureau of Chemistry, has been used quite successfully by many workers. However, it is not generally known. The method which we have worked out in order to meet the demands made upon the Bureau of Standards has the advantages over the abovementioned methods of giving more uniform results and higher yield at a lower cost, and is reported here that it may be useful to those requiring a supply of this sugar.

1 Lippmann, Die Chemie der Zuckerarten, III. Auflage, pages 698-700.: 1904. $54981^{\circ}-21-2$ 
One thousand five hundred $\mathrm{g}$ of lactose are dissolved in $3750 \mathrm{cc}$ of hot water containing $75 \mathrm{~g}$ of concentrated sulphuric acid. The solution is brought to a boil and then simmered for two hours. A thin paste of barium carbonate is then added to the hot solution until it reacts neutral to congo paper. The precipitate of barium sulphate is allowed to settle overnight, after which as much as possible of the supernatant liquid is drawn off. This liquid is filtered through a thin layer of active carbon placed on a moistened filter paper in a Büchner funnel. When all has passed through, the precipitate is placed on the filter, drained as dry as possible, and finally washed by drawing a little water through it. The filter, prepared with a small amount of carbon, as outlined, clarifies the solution and at the same time prevents the sulphate from passing through and gives a relatively rapid filtration.

The filtrate is concentrated under diminished pressure until it has a weight of $1650 \mathrm{~g}$. If a refractometer is available, the concentrated syrup should show a refractive index $\mathrm{n}_{\mathrm{v}}^{20}$ between $\mathrm{r} .5 \mathrm{I} 2 \mathrm{O}$ and $\mathrm{r} .5 \mathrm{I} 25$. The very thick syrup is warmed to between 60 and $70^{\circ}$ and $250 \mathrm{cc}$ of ethyl alcohol are dissolved in it by vigorous shaking. The solution is then poured into a beaker or jar and the remaining syrup is washed from the flask with $500 \mathrm{cc}$ of methyl alcohol. This is best done by adding the methyl alcohol to the flask portion wise and warming and shaking in a water bath. The whole solution is thoroughly mixed and seeded with some pure galactose crystals and allowed to crystallize.

The crystallization is generally complete in about four days, after which the crystals are filtered off, washed with a little methyl alcohol, then with 85 per cent ethyl alcohol, and finally with 95 per cent alcohol. They are then dried. The yield of the crude sugar is about 27 per cent of the lactose taken.

In order to purify the crude galactose, it is dissolved in water, making about a 25 per cent solution. To this is added a few cc of glacial acetic acid. It is then concentrated under diminished pressure to about 75 per cent total solids, warmed to 60 or $70^{\circ}$, transferred to a beaker, and 95 per cent alcohol added to saturation. Almost immediately the contents of the flask become solid. After standing overnight, the crystals are filtered from the mother liquor, washed, and dried. The yield is generally 82 to 83 per cent of the crude sugar taken. 
A thoroughly dried sample of this recrystallized product had the following properties:

$$
\begin{aligned}
& \text { Ash } \quad 0.034 \text { per cent. } \\
& {[\alpha]_{\mathrm{p}}^{\mathrm{3}} \quad=80^{\circ} .4 \text { (10.617 g per } 100.00 \mathrm{cc} \text { ). }} \\
& {[\alpha]_{\lambda-5462 \mathrm{~A}}^{00} \quad=95 .{ }^{\circ} 8 \text {. }}
\end{aligned}
$$

The values are only given, however, to identify the product. Work upon the thorough purification and the accurate determination of its specific rotation is in progress.

Washington, April 6, I921. 
1.

?

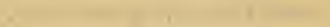

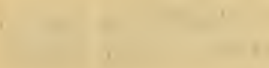

$$
1,100
$$

10 




(16) 
